\title{
CONSUMO VOLUNTÁRIO DE ENERGIA POR CÃES DE DIFERENTES RAÇAS
}

\author{
(Energy intake by dogs of different breeds)
}

Tatiane Aparecida Ramos, Larissa Wünsche Risolia, Simone Gisele de Oliveira, Ananda Portella Félix, Alex Maiorka ${ }^{1}$

1'Correspondência: sgoliveira@ufpr.br

RESUMO: O presente estudo teve como objetivo avaliar o consumo voluntário de energia por cães de diferentes raças. Para a realização do experimento, utilizou-se 16 cães adultos, machos e fêmeas, de raças distintas, alimentados com uma ração completa seca extrusada para cães em manutenção, uma vez ao dia durante 30 minutos. A quantidade fornecida foi $30 \%$ superior às necessidades de energia metabolizável de mantença (NEM). O delineamento foi inteiramente ao acaso e os resultados foram submetidos à análise de variância, sendo as médias comparadas pelo teste Tukey a $5 \%$ de probabilidade. Os cães da raça Labrador apresentaram consumo de $20 \%$ acima da energia recomendada, enquanto que os Huskies consumiram $26 \%$ menos energia que o recomendado para a raça. Em contrapartida os cães da raça Beagle apresentaram seu consumo de energia mais próximo ao recomendado pelo NRC. Diante dos resultados obtidos, conclui-se que cães da raça Labrador apresentaram maior consumo de energia dentre as raças avaliadas, seguidos por Basset hound, Beagle e Huskie siberiano

Palavras-chave: energia metabolizável; NRC; ração

\begin{abstract}
The present study aimed to evaluate the voluntary energy consumption by dogs of different breeds. For the experiment, we used 16 adult dogs, male and female, of different breeds, fed with a complete dry extruded ration for dog in maintenance, once a day for 30 minutes. The amount provided was $30 \%$ higher than the needs of metabolizable energy for maintenance (MEM). The delimitation was completely randomized and the results were submitted to analysis of variance and the means were compared by Tukey test at $5 \%$ probability. The Labrador breed dogs showed consumption of $20 \%$ above the recommended energy, while the Huskies consumed $26 \%$ less energy than recommended for the breed. In contrast Beagle dogs showed its power consumption closer to that recommended by NRC. Based on these results, it is concluded that the Labrador breed dogs had higher energy consumption among the breeds evaluated, followed by Basset hound, Beagle and Siberian Huskie.
\end{abstract}

Key Words: metabolizable energy; NRC; ration 


\section{INTRODUÇÃO}

Os animais de estimação, como os cães e gatos, ocupam cada vez mais espaço no cotidiano das pessoas, os quais se esforçam para oferecer o máximo de bem estar e saúde, visando longevidade a estes animais. Para isso, a qualidade dos alimentos a serem fornecidos é essencial para garantir ótima nutrição e saúde, e está diretamente ligada à ingestão de alimentos.

Ao mesmo tempo em que a ingestão é um comportamento necessário para a sobrevivência animal (Lebrun et al., 2006), ela obedece a diversos fatores bioquímicos e neuroendócrinos, que agem sobre o sistema nervoso (hipotálamo), promovendo a fome ou a saciedade (Felix et al., 2010). O hipotálamo exerce influência na auto-seleção de alimentos, nas respostas às dietas com alto conteúdo protéico ou desbalanceamento de aminoácidos, textura dietética, aprendizagem aversiva (experiências negativas), sentidos - olfato, tato e paladar - e nos efeitos de manipulações hormonais (Brito et al., 2009).

O controle da ingestão quantitativa e qualitativa voluntária de alimentos por cães é influenciado por diversos fatores inerentes ou não aos animais. Como fatores intrínsecos, cabe citar os anatomofisiológicos do organismo e as características e experiências individuais dos animais. Já, os fatores extrínsecos estão relacionados, principalmente, com as características do alimento, como: textura, sabor, forma, tamanho, umidade e temperatura (Félix et al., 2010).

Mas dentre as variantes que limitam 0 consumo voluntário de alimentos pelos cães, uma das principais está ligada à dieta, mais especificamente à energia dos alimentos (Burger, 1994). Devido à sua grande importância, fica fácil entender que a demanda por energia seja sempre a primeira a ser satisfeita pelo alimento de um animal. Independentemente das necessidades específicas que os cães tenham de ácidos graxos provenientes dos lipídios do alimento ou de aminoácidos essenciais procedentes das proteínas do alimento, os componentes energéticos do alimento serão utilizados, primeiramente, para satisfazer as demandas energéticas (Parreira, 2007). Entretanto, cães e gatos necessitam de diferentes níveis de energia para manutenção do metabolismo conforme o estado fisiológico, como mantença, crescimento, reprodução, lactação e atividade física (NRC, 2006), alterando, assim, a quantidade de alimento a ser ingerida.

Segundo Durrer \& Hannon (1962) e Miller et al. (1965), os cães são capazes de regular a ingestão de energia para satisfazer precisamente sua demanda calórica diária, quando lhes é fornecido um alimento nutricionalmente balanceado e moderadamente palatável. Entretanto, a comercialização de alimentos altamente palatáveis e o fato de algumas raças, como Labrador, Dachshund, Beagle e Basset hound apresentarem comportamento mais ativo, culminam na ingestão além das necessidades nutricionais. Sendo assim, objetivou-se avaliar o consumo de energia voluntário entre cães de diferentes raças.

\section{MATERIAL E MÉTODOS}

O experimento foi realizado utilizando 16 cães adultos, machos e fêmeas saudáveis, de quatro raças distintas: Labrador $(27,2+2,8 \mathrm{~kg})$, Beagle $(13,1+$ $1,2 \mathrm{~kg})$, Basset hound $(22,8+1,9 \mathrm{~kg}) \mathrm{e}$ Husky siberiano $(21,8+2,3 \mathrm{~kg})$, sendo quatro animais de cada raça. Os cães foram mantidos em baias de alvenaria com solário e alimentados uma vez ao dia, às 17 horas, com um alimento 
completo seco extrusado para cães em manutenção (Tabela 1). A energia metabolizável do alimento foi determinada in vivo em experimento prévio (Brito et al., 2009).

Tabela 1 - Ingredientes e composição química da dieta

\begin{tabular}{|c|c|}
\hline Ingredientes & $\mathrm{g} / \mathrm{kg}$ \\
\hline Milho & 440,0 \\
\hline Quirera de arroz & 40,0 \\
\hline Farelo de soja & 150,0 \\
\hline Farinha de carne e ossos & 150,0 \\
\hline Farinha de peixe & 10,0 \\
\hline Farinha de vísceras de frango & 140,0 \\
\hline Gordura de frango & 30,0 \\
\hline Palatabilizante (hidrolisado de vísceras de ave) & 30,0 \\
\hline Premix vit/min' & 5,0 \\
\hline Cloreto de sódio & 5,0 \\
\hline \multicolumn{2}{|c|}{ Composição química analisada (\% na matéria seca) } \\
\hline Matéria seca (MS) \% & 89,36 \\
\hline Matéria orgânica (MO) & 90,04 \\
\hline Matéria mineral (MM) & 9,96 \\
\hline Proteína bruta (PB) & 30,59 \\
\hline Extrato etéreo ácido (EEA) & 8,51 \\
\hline Fibra bruta (FB) & 2,34 \\
\hline Extrativos não-nitrogenados (ENN) ${ }^{2}$ & 37,96 \\
\hline Energia metabolizável $(\mathrm{kcal} / \mathrm{g})(\mathrm{EM})^{\sigma}$ & 3,12 \\
\hline \multicolumn{2}{|c|}{ 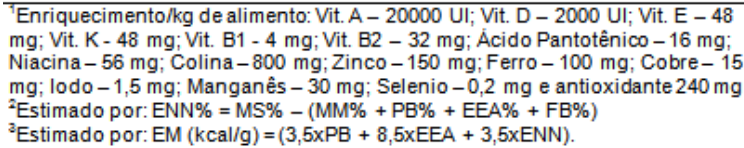 } \\
\hline
\end{tabular}

O alimento fornecido aos animais foi pesado individualmente, sendo a quantidade $30 \%$ superior às necessidades de energia metabolizável de mantença (NEM), estimada por: NEM $(\mathrm{kcal}$. dia- 1$)=130 \times$ peso corporal 0,75 , preconizada pelo NRC (2006). A água foi fornecida à vontade. Os cães foram alimentados previamente por dois dias para adaptação e o alimento ofertado durante 30 minutos. Após este tempo, as sobras foram quantificadas e 0 consumo de energia por $\mathrm{kg}$ de peso metabólico (PM) foi determinado por: [alimento ingerido $(\mathrm{g}) \times \mathrm{EM}$ alimento $(\mathrm{kcal} / \mathrm{kg}) /$ peso corporal0,75 $(\mathrm{kg})]$.

Os cães foram alimentados previamente por dois dias para adaptação à dieta, seguidos por 18 dias de coleta de dados, totalizando 72 observações por raça. $O$ delineamento utilizado foi o inteiramente ao acaso em parcela subdividida no tempo, sendo os dias a parcela $e$ as raças as subparcelas. Os resultados foram submetidos à análise de variância e as médias comparadas pelo teste Tukey a $5 \%$ de probabilidade.

\section{RESULTADOS E DISCUSSÃO}

Além de diferir quanto aos estádios fisiológicos, à necessidade energética dos cães varia conforme raça, temperamento, idade e atividade do animal, como também pela temperatura ambiente, entre outros fatores (Kienzle \& Rainbird, 1991). Nesse contexto, dependendo da raça do cão, o olfato pode variar em função da superfície da mucosa olfativa, do número de receptores, assim como da anatomia facial, que determina a direção da corrente aérea no animal (Pizzato \& Domingues, 2008).

James \& Mccay (1949) relataram que algumas raças de cães, como os Labradores, consomem mais energia do que necessitam para manutenção, caso tenham livre acesso ao alimento, sendo esta hipótese reforçada por Saad (2004) considerando que animais desta raça apresentam apetite exacerbado e, quando alimentados à vontade, podem desenvolver obesidade.

Em ensaio de palatabilidade Roque et al., (2007), constataram que Labradores apresentaram maior consumo de kcal de Energia Metabolizável (EM), por $\mathrm{kg}$ de peso metabólico, comparados à Beagles, e resultado semelhante foi observado no presente estudo, em que cães da raça Labrador apresentaram maior consumo de energia dentre as raças avaliadas, seguidos pelos Basset hound, Beagles e Huskies siberianos (Tabela 2).

\begin{tabular}{|c|c|}
\hline Raça & $\begin{array}{c}\text { Consumo de Energia } \\
\left(\mathrm{kcal}^{\mathrm{kgg}} \text { peso }^{0,75}\right)\end{array}$ \\
\hline Labrador & $165,6^{\mathrm{a1}}$ \\
\hline Basset hound & $149,1^{\circ}$ \\
\hline Beagle & $134,1^{\mathrm{c}}$ \\
\hline Husky siberiano & $97,8^{\circ}$ \\
\hline
\end{tabular}


Considerando a variável "temperatura", em temperatura ambiente média de $26^{\circ} \mathrm{c}$, cães labradores podem ingerir em média $20 \%$ a mais de energia que o recomendado pelo NRC (2006), enquanto cães da raça Husky Siberiano podem consumir até $35 \%$ a menos do recomendado (Brito et al., 2009), podendo justificar 0 resultados encontrados, uma vez que a temperatura ambiente era média de $26,5^{\circ} \mathrm{C}$. No presente estudo, os cães da raça Beagle foram os que apresentaram ingestão de energia mais próxima às recomendações (130 kcal/kg PM/dia) do NRC (2006).

Analisando a quantidade de energia metabolizável preconizada a ser ingerida, o NRC (2006) descreve que cães da raça Labrador, mantidos em canil, apresentam necessidade de energia de $138 \mathrm{kcal} / \mathrm{kg} \mathrm{PM} / \mathrm{dia}$. Entretanto, no presente estudo, os Labradores ingeriram $20 \%$ mais energia que o recomendado, enquanto que os Huskies consumiram $26 \%$ menos energia que o recomendado para a raça (132 kcal/kg PM/dia), concordando, para ambos os dados, que em temperatura média de $26,5^{\circ} \mathrm{C}$ há excesso e redução de ingestão de energia, respectivamente.

A superalimentação deve ser reparada, pois pode culminar em problemas fisiológicos. A ingestão de energia acima das necessidades do animal, aliada à vida sedentária da maioria dos cães de estimação, pode acarretar em obesidade e problemas de saúde decorrentes desta, como hipertensão e Diabetes melittus tipo II (Felix et al., 2010). Entretanto, aproximadamente, $30 \%$ dos cães e gatos domésticos podem ter sobrepeso (NRC, 2006).

Para o reduzido consumo de energia pelos Huskies, Grandjean \& Paragon (1993), explicam que animais adultos em baixa atividade apresentam menor NEM (100-110 kcal/kg PM/dia), devido ao fato desta raça apresentar menor gasto energético para a termorregulação (isolamento térmico pela pelagem), maior rendimento do metabolismo energético, temperatura corporal menor que a encontrada em outras raças e temperamento mais tranquilo. Além disso, por serem oriundos de climas frios, os Huskies são sensíveis a temperaturas elevadas, como demonstrado por Durrer \& Hannon (1962), em que cães da raça Husky no inverno ingeriram, em média, 193,3 $\mathrm{kcal} / \mathrm{kg}$ Peso Metabólico /dia, ao passo que no verão, a ingestão de energia caiu para $118,3 \mathrm{kcal} / \mathrm{kg}$ Peso Metabólico/dia. Tal fato é explicado por que com o declínio da temperatura ambiente o organismo deve gerar mais calor na tentativa de manter a temperatura corporal, para isso aumenta-se a ingestão de alimentos.

\section{CONCLUSÃO}

Dentre as raças avaliadas, Labradores apresentam a maior ingestão de energia, enquanto que os Huskies a menor ingestão, e os Beagles a ingestão de energia mais próximo às recomendações pelo NRC. Futuros estudos são sugeridos para avaliar o consumo e as necessidades de energia de cães de diferentes raças, gêneros, estádios fisiológicos e submetidos a diferentes temperaturas e atividades físicas.

\section{NOTAS INFORMATIVAS}

Aprovado pelo CEUA do Setor de Ciências Agrárias da UFPR Protocolo No. 027/2011, em 14/10/2011.

\section{REFERÊNCIAS}

BRITO, C.B.M. Efeito de diferentes níveis de umidade com e sem utilização de antifúngico em dietas para cães. Dissertação de Mestrado em 
Ciências Veterinárias - Setor de Ciências Agrárias, Universidade Federal do Paraná. Curitiba, 2009.

BURGUER, I.H. Energy Needs of Companion Animals: Matching Food Requirements Throughout the Life Cycle. The Journal of Nutrition. p.2584s-2593s, 1994.

DURRER, J.L.; HANNON, J.P. Seasonal variations in caloric intake of dogs living in an artic environment. American Journal of Physiology. v.280, p.202-375, 1962.

FELIX, A.; OLIVEIRA, S.G.; MAIORKA, A. Fatores que interferem no consumo de alimentos em cães e gatos. In: VIEIRA, S.L. Consumo e preferência alimentar de animais domésticos. Londrina - PR. 287p. Publicado em 2010. 162-199p.

GRANDJEAN, D.; PARAGON, B.M. Nutrition of racing and working dogs. Part II. Determination of energy requirements and the nutritional impact of stress. In: 40th

JAMES, W.T.; MCCAY, C.M. A study of food intake, activity and digestive efficiency in different type dogs. Nutrition of the dog. 2.ed. Ithaca:Comstock Publishing Co., p.414-416, 1949.

KIENZLE, E.; RAINBIRD, A. Maintenance energy requirement of dogs: what is the correct value for the calculation of metabolic body weight in dogs? Journal of Nutrition, v.121, p.3940, 1991.

LEBRUN, B.; BARIOHAY, B.; JEAN, A. Control of food intake: neurobiological aspects. Bull. Acad. Vét. France. No4, p. 289-300, 2006.

MILLER, $\mathrm{H}$. Essential nutrients and their role in metabolism. Basic guide to canine nutrition. 1ed. New York: Gaines Dog Research Center. Cap.3, p.12-14, 1965.

NACIONAL RESEARCH COUNCIL - NRC. Nutrient Requirements of Dogs and Cats. National Academy Press. Washington, 2006, 424p.

PARREIRA, P.R. Aspectos fundamentais da determinação da exigência energética de cães domésticos. Revista Acadêmica, Curitiba, v.5, nำ, p.415-422. Outubro/Dezembro 2007.

PIZZATO, D.A.; DOMINGUES, J.L. Palatabilidade de alimentos para cães. Revista Eletrônica Nutritime, v.5, n², p.504-511, Artigo Número 51. Março/Abril 2008.

SAAD, F.M.O.B., SAAD, C.E.P. História evolutiva na alimentação e controle de consumo dos cães e gatos. In: b. UFLA - Universidade Federal de Lavras, FAEPE-Fundação de Apoio ao Ensino, Pesquisa e Extensão. Lavras - MG. Lavras: UFLA/ FAEPE, 44p, 2004. 